\title{
BIOPROSPEKSI ANTIBAKTERI BEBERAPA JENIS SPONS DARI PERAIRAN PANGALISANG BUNAKEN
}

\author{
(Some Antibacterial Bioprospection Types of Sponge from Pangalisang \\ Bunaken Water) \\ Jeksen William Liem, ${ }^{1 *}$ Robert A. Bara, ${ }^{1}$ Deiske A. Sumilat, ${ }^{1}$ Veibe Warouw, ${ }^{1}$ Fitje \\ Losung, ${ }^{1}$ Adnan Wantasen. ${ }^{2}$
}

1. Program Studi IImu Kelautan, Fakultas Perikanan dan IImu Kelautan, Universitas Sam Ratulangi, Manado.

2. Program Studi Manajemen Sumberdaya Perairan, Fakultas Perikanan dan IImu Kelautan, Universitas Sam Ratulangi, Manado.

*e-mail : robert.bara@unsrat.ac.id: jeksenliem@yahoo.com

Indonesian is the largest archipelagic country in the world that has a coastline of 99,093 $\mathrm{km}^{2}$ which is rich in coral reefs and other marine biota. One of the biota that has been studied are sponges. Indonesian Waters is one of the largest sponge distribution in the world and it is estimated there are about 830 species living in this region only. Several species of sponges were taken from Pangalisang in Bunaken waters, e.q. Liosina paradoxa, Theonella sp, Aoptos chromis, Callyspongia aerizusa and Haliclona continued by extraction using Ethanol $96 \%$. The sponge extract then tested their antibacterial activity using Disk Diffusion Kirby-Bauer Method. The results show that only A.chromis and $C$.aerizusa extracts were active against $B$.megaterium with the average of $17.6 \mathrm{~mm}$ and $15.0 \mathrm{~mm}$ in diameter, respectively. Whereas in $E$. coli, only $A$. chromis extract shows antibacterial activity with $15.0 \mathrm{~mm}$ in diameter. As a conclussion, from 5 different sponge extracts, only A.chromis and C.aerizusa extracts show activity against Gram positive B.megaterium, However, only A.chromis extract shows activity against Gram negative E. coli.

\footnotetext{
Keywords : Bacillus megaterium (DSM 32T), Escherichia coli (DSM 489), antibacterial activity sponge

Indonesia merupakan negara kepulauan terbesar di dunia yang mempunyai panjang pantai $99.093 \mathrm{~km}^{2}$ yang kaya akan terumbu karang dan biota laut lainnya. Salah satu biota yang banyak diteliti adalah spons. Wilayah laut Indonesia merupakan salah satu pusat penyebaran terbesar spons di dunia dan diperkirakan terdapat sekitar 830 spesies yang hidup tersebar di wilayah ini. Sampel penelitian yaitu beberapa jenis spons yang diambil dari Perairan Pangalisang Bunaken. Metode yang digunakan pada penelitian ini untuk pengujian aktivitas antibakteri dari ekstrak sampel spons adalah metode difusi agar. Hasil pengujian aktivitas antibakteri dari kelima ekstraksi memperlihatkan hanya ekstrak A.chromis dan C.aerizusa yang aktif terhadap bakteri B.megaterium dengan nilai hambat rata-rata sebesar $17,6 \mathrm{~mm}$ dan 15,0 $\mathrm{mm}$, sedangkan pada bakteri E.coli hanya ekstrak A.chromis yang memiliki aktivitas antibakteri dengan nilai rata-rata $15,0 \mathrm{~mm}$. Kesimpulan dari penelitian ini, telah dilakukan ekstraksi 5 spons yaitu, Liosina paradoxa, Theonella sp, Aoptos chromis, Callyspongia aerizusa dan Haliclona sp. menggunakan metode maserasi yakni etanol. Dari 5 spons yang berhasil di uji aktivitas antibakteri hanya ekstrak A.chromis dan ekstrak C.aerizusa yang menunjukan aktivitas daya hambat terhadap bakteri B.megaterium, sedangkan pada bakteri E.coli hanya ekstrak A.chromis yang memiliki zona hambat dari kelima ekstrak yang di uji.
}

Kata kunci : Bacillus megaterium (DSM 32T), Escherichia coli (DSM 489), Aktivitas Antibakteri Spons 


\section{PENDAHULUAN}

Indonesia merupakan negara kepulauan terbesar di dunia yang mempunyai panjang pantai $99.093 \mathrm{~km}^{2}$ yang kaya akan terumbu karang dan biota laut lainnya. Salah satu biota yang banyak diteliti adalah spons. Wilayah

laut Indonesia merupakan salah satu pusat penyebaran terbesar spons di dunia dan diperkirakan terdapat sekitar 830 spesies yang hidup tersebar di wilayah ini (Van Soest, 1989; Badan Informasi Geospasial, 2015). Spons merupakan salah satu komponen biota penyusun terumbu karang yang mempunyai potensi senyawa bioaktif yang belum banyak dimanfaatkan. Hewan laut ini mengandung senyawa aktif yang lebih besar dibandingkan dengan senyawasenyawa yang dihasilkan oleh tumbuhan darat (Muniarsih dan Rachmaniar. 1999). Untuk menjaga kelangsungan hidup dan pertahanan dirinya, spons menghasilkan metabolit primer dan metabolit sekunder.

Spons mampu memproduksi beragam metabolit sekunder yang memiliki potensi sebagai senyawa bioaktif antibakteri. Semula hal ini berangkat dari asumsi bahwa metabolit sekunder merupakan pertahanan kimia alami bagi biota tertentu dapat pula melindungi mahkluk hidup lainnya. Bertolak dari asumsi potensi sekunder maka kemudian berkembanglah penelitian pemanfaatan metabolit sekunder untuk kesehatan manusia dengan meneliti antibakteri dari spons (Undap, 2016; Ngantung et al. 2016; Luissandy et al. 2017).

Permasalahan resistensi bakteri terhadap beberapa jenis obat antibakteri menimbulkan banyak masalah dalam pengobatan penyakit Senyawa antibakteri adalah zat yang dapat mengganggu pertumbuhan bahkan dapat mematikan bakteri dengan cara merusak sistem metabolisme mikroba tersebut. Salah satu organisme yang sangat berpotensi sebagai sumber obat antibakteri adalah spons, hewan ini telah menjadi perhatian utama dalam berbagai riset senyawa bioaktif yang dikandungnya (Schunack et al. 1990, Madigan, 2005). Menanggapi permasalahan di atas, maka penelitian ini dilakukan untuk menguji biota spons dalam upaya penemuan senyawa bioaktif antibakteri untuk dijadikan sebagai bahan baku obatobatan yang dapat membunuh bakteri.

Mendapatkan beberapa jenis spons yang diambil dari Perairan Pangalisang Bunaken dan Menguji aktivitas antibakteri beberapa ekstrak spons menggunakan metode maserasi terhadap bakteri Bacillus megaterium DSM 32T dan Escherichia coli DSM 489.

\section{METODE PENELITIAN}

\section{Tempat dan Waktu Penelitian}

Penelitian ini dilakukan selama \pm 4 minggu. Sampel penelitian yaitu beberapa jenis spons yang diambil dari Perairan Pangalisang Bunaken, sedangkan pengujian dan analisis data dilakukan di Laboratorium Biologi Molekuler dan Farmasitika Laut Fakultas Perikanan dan IImu Kelautan Universitas Sam Ratulangi, Manado.

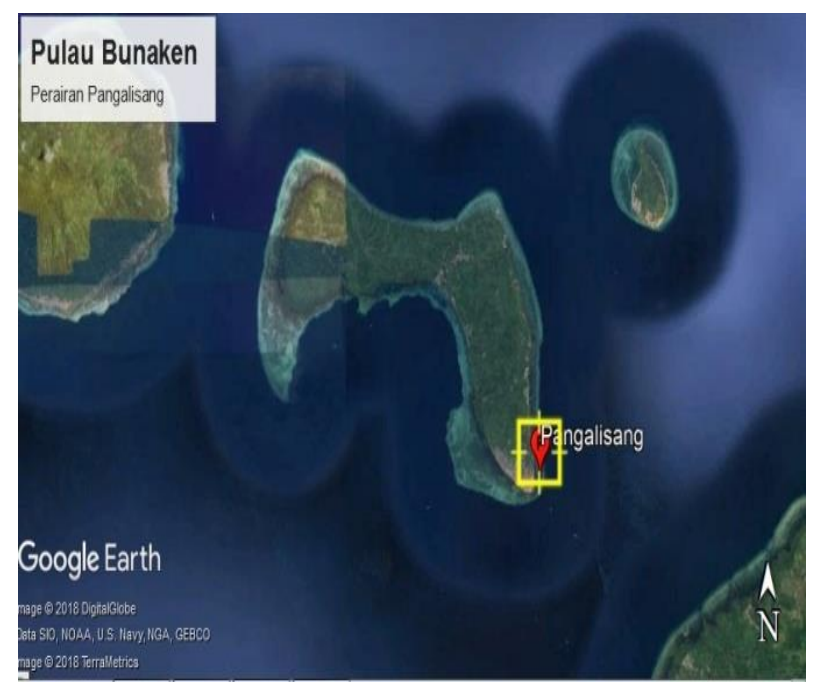

Gambar 1. Lokasi Pengambilan sampel Spons di Perairan Pangalisang Bunaken.

\section{Ekstraksi Sampel Spons}


Proses ekstraksi sampel spons dilakukan dengan cara spons dipotong kecil untuk dimasukkan ke dalam botol plastik yang sudah terisi etanol 95\% sebanyak $250 \mathrm{ml}$. kemudian sampel spons dimaserasi/direndamkan selama 1x24 jam. Kemudian itu dilakukan penyaringan sampel, bertujuan untuk memisahkan antara debris/ampas sampel spons dengan filtrat

Setelah dilakukan filtrasi, spons yang terkandung di dalam etanol kemudian dievaporasi atau diuapkan hingga kering dengan menggunakan alat rotary evaporator. Proses evaporasi terus dilakukan hingga etanol benar-benar kering dan terpisah untuk memperoleh ekstrak kasar spons. Hasil ekstrak kasar spons kemudian dimasukkan ke dalam botol untuk di uji lebih lanjut.

\section{Pembuatan Media Cair dan Media Padat}

Media cair B1 dibuat untuk kultur bakteri $B$. megaterium dan E.coli. Banyaknya bahan pembuatan media cair B1 untuk masing-masing erlenmeyer yaitu pepton sebanyak $3 \mathrm{~g}$, ekstrak daging $2 \mathrm{~g}$, natrium klorida ( $\mathrm{NaCl}) 2 \mathrm{~g}$, lalu dimasukkan ke dalam gelas erlenmeyer dan dilarutkan dengan aquades $/ \mathrm{dH}_{2} \mathrm{O}$ sebanyak $1000 \mathrm{ml}$, setelah itu ditutup dan dibungkus menggunakan kertas aluminium foil untuk di autoklaf pada suhu $121^{\circ} \mathrm{C}$ selama kurang lebih 15 menit (Atlas dan Snyder, 2014).

Sedangkan pembuatan media padat B1 digunakan bahan-bahan dengan takaran seperti pepton $3 \mathrm{~g}$, ekstrak daging $2 \mathrm{~g}$, natrium klorida ( $\mathrm{NaCl}) 2 \mathrm{~g}$, agar $15 \mathrm{~g}$, dan dimasukkan kedalam gelas erlenmeyer lalu dilarutkan dengan aquades $/ \mathrm{dH}_{2} \mathrm{O}$ sebanyak $1000 \mathrm{ml}$ (Atlas dan Snyder, 2014). setelah itu ditutup dan dibungkus menggunakan kertas aluminium foil untuk diautoklaf seperti yang disebut di atas.

\section{Pengujian Aktivitas Antibakteri}

Metode yang digunakan pada penelitian ini untuk pengujian aktivitas antibakteri dari ekstrak sampel spons adalah metode difusi agar (disc diffusion Kirby Bauer). Kertas cakram yang digunakan pada pengujian aktivitas antibakteri ini berukuran $6 \mathrm{~mm}$ dengan daya serap $50 \mu \mathrm{l}$ pada tiap kertas cakram. konsentrasi yang digunakan $100 \mathrm{mg} / \mathrm{ml}$ dengan 3 kali pengulangan.

\section{HASIL DAN PEMBAHASAN}

Hasil morfologi 5 spons yang diperoleh yaitu dengan ciri-ciri berbentuk bantal dan warna yang berbeda. Hasil identifikasi makroskopik berdasarkan buku identifikasi spons dari (Hooper dan Voogd, 2002). kelima sampel spons tersaji dalam rangkaian (Gambar 2).

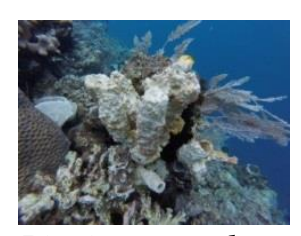

Liosina paradoxa

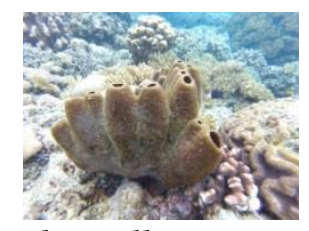

Theonella sp.
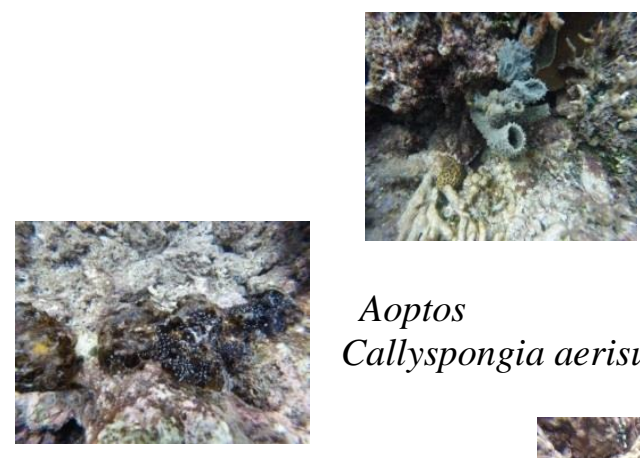

Aoptos chromis Callyspongia aerisuza

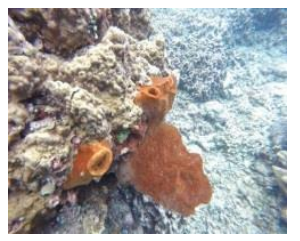

Haliclona sp.

Gambar 2. Sampel spons yang dikoleksi dari Perairan Pangalisang Bunaken.

\section{Hasil pengujian aktivitas antibakteri}

Pengujian aktivitas antibakteri dari beberapa jenis spons, hasil yang didapat melalui pengamatan yang dilakukan selama 1x24 jam dalam masa inkubasi dengan 3 
kali pengulangan untuk masing-masing kedua bakteri B.megaterium dan E.coli.

Aktivitas antibakteri tersebut terlihat pada $A$. chromis dan $C$. aerizusa dari 3 kali pengulangan terhadap bakteri B.megaterium dan pada bakteri E.coli hanya ekstrak A.chromis dan ekstrak C.aerizusa yang memperlihatkan adanya aktivitas zona hambat pada Gambar (A). Sedangkan pada Gambar (B) hanya ekstrak A.chromis yang memperlihatkan aktivitas antibakteri terhadap bakteri E.coli. Nilai rata-rata pengukuran zona hambat beberapa ekstrak spons terhadap uji bakteri B.megaterium dan Bakteri E.coli dapat dilihat pada (Tabel 1).

Hasil pengujian aktivitas antibakteri dari kelima ekstraksi memperlihatkan ekstrak A.chromis dan C.aerizusa aktif terhadap bakteri B.megaterium dengan nilai hambat rata-rata berturut-turut sebesar $17,6 \mathrm{~mm}$ dan $15,0 \mathrm{~mm}$.

Ekstrak $A$. chromis memperlihatkan adanya aktivitas antibakteri yang cukup kuat dibandingkan C.aerizusa dan bahkan lebih besar dibandingkan dengan kontrol positif. L. paradoxa, Theonella sp. Haliclona sp. tidak memperlihatkan adanya zona hambat, kemungkinan ketiga spesies spons tidak memiliki senyawa dengan aktivitas antibakteri.

(A)
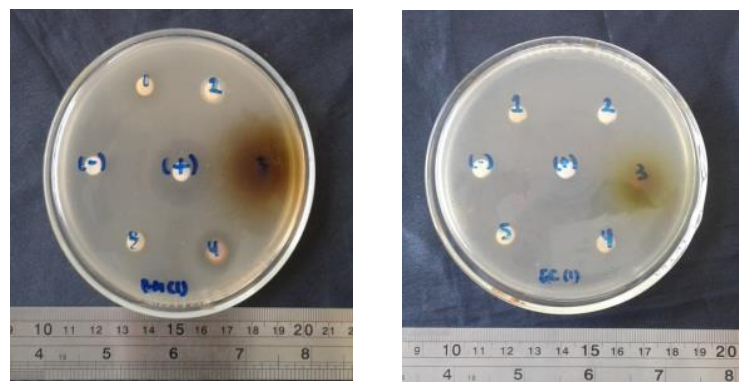

Gambar 3. Aktivitas Antibakteri beberapa ekstrak spons pada Bakteri B.megaterium (Gambar A) dan E.coli (Dokumentasi pribadi, 2018)
Tabel 1. Pengukuran diameter zona hambat dari beberapa ekstrak spons pada bakteri $B$,.megaterium dan E.coli.

\begin{tabular}{|c|c|c|c|}
\hline No & $\begin{array}{l}\text { Ekstrak } \\
\text { Spons }\end{array}$ & $\begin{array}{c}\text { Rerata } \\
\text { (B.M) } \\
\text { (DSM 32T) }\end{array}$ & $\begin{array}{r}\text { Rerata } \\
(\text { E.C) } \\
\text { DSM 489) }\end{array}$ \\
\hline & Liosina. $\mathrm{p}$ & - & - \\
\hline & Theonella sp & - & - \\
\hline & A.chromis & $17,6 \pm 1,1$ & $15,0 \pm 0,0$ \\
\hline & C. aerizusa & $15,0 \pm 1,0$ & - \\
\hline & Haliclona sp & - & - \\
\hline & Kontrol (+) & $25,0 \pm 0,0$ & $33,0 \pm 0,0$ \\
\hline & Kontrol (-) & - & - \\
\hline
\end{tabular}

Pada Pengujian aktivitas antibakteri hanya A.chromis yang memiliki aktivitas terhadap bakteri uji tersebut, keempat ekstrak lainnya termasuk ekstrak $C$.aerizusa yang sebelumnya aktif terhadap bakteri.

Ekstrak A.chromis menunjukkan aktivitas antibakteri pada kedua bakteri uji, aktivitas antibakteri A.chromis bersifat spektrum luas, sedangkan C.aerizusa hanya aktif terhadap bakteri B.megaterium yang memperlihatkan senyawa antibakteri yang dikandungnya berspektrum sempit.

Pada penelitian ini terdapat dua ekstrak spons yang memperlihatkan adanya aktivitas antibakteri terhadap bakteri uji B.megaterium dan E.coli. Beberapa penelitian terhadap spons pernah dilakukan oleh Losung et al. (2002) dan Nugraha et al. (2014), berhasil mengisolasi senyawa antibakteri yang dapat menghambat pertumbuhan bakteri Gram positif dan Gram negatif.

Penelitian selanjutnya dapat diarahkan pada penemuan kandidat obatobatan antibakteri baru berasal dari spons terutama dengan aktivitas antibakteri yang spesifik terhadap Gram negatif. Sejauh ini 
pengendalian infeksi bakteri Gram negatif seringkali menjadi kendala dalam dunia kedokteran. Hal ini diakibatkan oleh karakteristik bakteri kelompok Gram negatif yang memiliki dinding peptidoglikan yang cukup padat dan kompak sehingga menghambat proses internalisasi senyawa obat untuk mampu mempengaruhi mekanisme seluler dari bakteri. Disamping adanya "effux-pump" mechanism" suatu mekanisme untuk mengeluarkan senyawasenyawa yang tidak dibutuhkan dalam proses biotransformasi seluler bakteri melalui sistem sekresi mereka (Poole, 2007; Posangi et al. 2014).

Etanol digunakan sebagai kontrol negatif pada penelitian ini. Kontrol negatif tidak menunjukkan adanya zona hambat terhadap kedua bakteri uji.

\section{KESIMPULAN}

Beberapa hal yang disimpulkan dari penelitian ini yaitu:

Lima spons yang tumbuh dari Perairan Pangalisang yaitu Liosina paradoxa, Theonella sp, Aoptos chromis, Callyspongia aerizusa, dan Haliclona $s p$. diambil dan diekstraksi dengan menggunakan metode maserasi menggunakan etanol.

Dari kelima jenis spons yang di uji aktivitas antibakteri, hanya ekstrak A.chromis dan ekstrak C.aerizusa yang menunjukan aktivitas zona hambat terhadap pertumbuhan bakteri B.megaterium. Ekstrak Liosina paradoxa, Theonella sp, dan Haliclona $s p$, tidak memperlihatkan adanya zona hambat. Sedangkan pada bakteri E.coli hanya ekstrak A.chromis yang memiliki zona hambat dari kelima ekstrak yang di uji.

\section{DAFTAR PUSTAKA}

Atlas, R.M., Snyder. J.W. 2014. Handbook of medical for clinical and public health microbiology. Francis: CRC Press.
Badan Informasi Geospasial. 2015. Pentingnya informasi geospasial untuk menata laut Indonesia. http:// big.go.id/berita-surta/show/ pentingnya-informasi-geospasialuntuk-menata-laut-indonesia. Diakses Pada 26 April 2018.

Losung. F., Mangindaan, P.E.R., Posangi, J. 2002. Studi Tentang substansi antibakteri dari ekstrak spons. 24. Tesis . Pascasarjana Universitas Sam Ratulangi.

Luissandy, Sumilat, D.A., Lintang, R.A.J. 2017. Bioaktivitas antibakteri fraksi ODS Spons agelas sp. dari Perairan Pulau Bunaken. Jurnal Pesisir dan Laut Tropis 2(1):22-30.

Muniarsih T., Rachmaniar R. 1999. Isolasi substansi bioaktif antimikroba dari spons asal Pulau dari Kepulauan Seribu. Prosidings seminar bioteknologi kelautan Indonesia l'98. Jakarta 14 - 15 Oktober 1998: Lembaga IImu Pengetahuan Indonesia, Jakarta.

Madigan M. 2005. Brock biology of microorganisme, London: Prentice Hall.

Ngantung, A.E.C, Bara, R.A, Sumilat, D.A 2016. Uji aktivitas antibakteri dari spons. Dictyonella funicularis dan Phyllospongia lamellosa yang diambil dari Perairan Bunaken. Jurnal Pesisir dan Laut Tropis. 2(1):10-16.

Nugraha, 2014. Isolasi dan Uji Aktivitas Antibakteri Senyawa Turunan 1, 2Dioksana dari Spons Laut Plakortis simplex. Universitas Gadjah Mada Yogyakarta.

Poole, K. 2007. Efflux pumps as antimicrobial resistance mechanism. 39 (3):162-176.

Posangi, J, Bara, R. 2014. Analisis aktivitas dari jamur endofit yang terdapat 
dalam tumbuhan bakau Avicennia marina di Tasik Ria Minahasa " Jurnal Pesisir dan Laut tropis, 1 (1):30-38.

Schunack, W, Mayer K, Haake, M. 1990. Senyawa obat. Wattimenna J R, Subito, penerjemah. UGM press, Yogyakarta. edisi ke-2.

Undap. N.I.J. 2016. Senyawa antibakteri spons. smenospongia aurea, strepsichordaia sp, Agelas tubulata dan Phyllospongia sp. dari Perairan Pantai Malalayang Manado terhadap pertumbuhan strain bakteri. Tesis. Pascasarjana Ilmu Perairan. Universitas Sam Ratulangi. Manado.

Van Soest, R.W.M. 1989. The Indonesian sponges fauna : A Status Report. Ne \&.J.Sea Res 23:223-30.

Voogd, N, Soest, V. 2002. Indonesia Sponges of the genus petrosia vosmaer (Depospongiae:

Haplosclerida). Journal zool. Med. leiden 76. 11-13. 